\title{
Levantamento parasitológico e sorológico de Leishmaniose em cães da Unidade de Controle de Zoonoses (UCZ) de Guaraí (TO)
}

Os cães são atingidos por diversos patógenos transmitidos o que pode acarretar testes falso-positivo quando existe reação cruzada. Para identificar essas reaçõe foi realizado um levantamento parasitológico e sorológico de Leishmaniose em cães da Unidade de Controle de Zoonoses (UCZ) de Guaraí-TO, em 10 amostras de sangue periférico, linfa através de punção aspirativa nos linfonodos do membro posterior esquerdo e punção aspirativa por medula óssea no esterno. Adicionalmente foi realizado teste imunocromatográfico (DPP ${ }^{\circledR}$ LVC Bio-Manguinhos/FIOCRUZ), e confirmados com pesquisa de parasitos através de exame parasitológico direto. Embora todos se apresentaram positivos no teste rápido, o resultado se comprovou significativamente nas amostras examinadas no parasitológico apresentando prevalência de $100 \%$ para Leishmania, $60 \%$ para Babesia e $30 \%$ para Ehrlichia. O teste rápido (DPP ${ }^{\circledast}$ ) mostrou-se eficiente no presente estudo, sendo que em todos os animais positivos foram confirmados no exame parasitológico.

Palavras-chave: Cães; Leishmania spp; Babesia spp; Ehrliquia spp; Parasitológico direto.

\section{Parasitological and serological survey of Leishmaniasis in dogs of the Control Unit of Zoonoses (UCZ) of Guaraí (TO)}

\begin{abstract}
Dogs are affected by several transmitted pathogens, which can lead to false-positive tests when there is a cross-reaction. To identify these reactions, parasitological and serological survey of Leishmaniasis was performed in dogs from the Control Unit of Zoonoses (UCZ) of Guarai-TO, in 10 samples of peripheral blood, lymph via aspiration puncture in the lymph nodes of the left hind limb and aspiration puncture by bone marrow in the sternum. In addition, immunochromatographic test (DPP ${ }^{\circ}$ LVC Bio-Manguinhos / FIOCRUZ) was performed and confirmed with parasite research through direct parasitological examination. Although all were positive in the rapid test, the results were found to be statistically significant in the parasitological samples, with a prevalence of $100 \%$ for Leishmania, $60 \%$ for Babesia and $30 \%$ for Ehrlichia. The rapid test (DPP ${ }^{\otimes}$ ) was efficient in the present study, and in all the positive animals were confirmed in the parasitological examination.
\end{abstract}

Keywords: Dogs; Leishmania spp; Babesia spp; Ehrlichia spp; Direct parasitological.

Topic: Parasitologia

Reviewed anonymously in the process of blind peer.
Received: $16 / 11 / 2018$

Approved: 27/01/2019
Fabiana Teodoro Gomes

Faculdade Guaraí, Brasil

http://lattes.cnpq.br/4031908089594053

fabianabmed@gmail.com

Thainara Anjos Barros

Faculdade Guaraí, Brasil

http://lattes.cnpq.br/6580256274245989

thainara-barros96@hotmail.com

Lauriene Dias Rosa

Faculdade Guaraí, Brasil

http://lattes.cnpq.br/0759579930649683

dlauriene@gmail.com

\author{
Aluísio Vasconcelos de Carvalho (iD \\ Faculdade Guaraí, Brasil \\ http://lattes.cnpq.br/5200758055263996 \\ http://orcid.org/0000-0002-3793-3133 \\ aluisiovasconcelos@gmail.com
}

DOI: 10.6008/CBPC2674-6484.2019.001.0001

Referencing this:

GOMES, F. T.; BARROS, T. A.; ROSA, L. D.; CARVALHO, A. V.

Levantamento parasitológico e sorológico de Leishmaniose em cães da Unidade de Controle de Zoonoses (UCZ) de Guaraí (TO). Medicus, v.1, n.1, p.1-9, 2019. DOI: http://doi.org/10.6008/CBPC26746484.2019.001.0001 


\section{INTRODUÇÃO}

As leishmanioses são patologias lesivas alastrando 98 países do mundo acarretado por distintos protozoários da família Trypanosomatidae, gênero Leishmania (FARIA et al., 2012; PASTORINO et al., 2002). É uma parasitose com ciclo biológico heteroxênico envolvendo diversos hospedeiros no processo: os flebotomíneos e mamíferos (GONTIJO et al., 2004; FOCACCIA et al., 2005).

A infecção da Leishmania Chagasi, apontada como principal agente etiológico da Leishmaniose Visceral-LV se dá pelo repasto sanguíneo que ocorre através da picada da fêmea de insetos dípteros da família Psychodidae, tendo como o principal vetor Lutzomya longipalpis (MONTEIRO et al., 2005) e o cão (Canis familiaris) como reservatório nos espaços urbanos (NOGUEIRA et al., 2009).

A doença tem um histórico longo sendo diagnosticada a princípio na Grécia em 1835 e em 1869 na Índia recebeu o nome de Kala-Zar que ficou assim conhecida mundialmente. Apenas em 1913 foi apontado no Paraguai o primeiro caso aborígene do Brasil. Acredita-se que possivelmente a LV tenha chegado ao Brasil através de cães infectados trazidos da Europa. Desde então foram descritos muitos casos da doença, como os diagnosticados em 1934 por Henrique Penna que durante um estudo epidemiológico de febre amarela detectou 41 casos de Leishmaniose Visceral- LV encontrados em oito Estados brasileiros (BASTOS et al., 2015). Após 20 anos, registrou em Sobral (CE) o primeiro surto da doença (SILVINO et al., 2017).

A LVC primordialmente era considerada uma zoonose distinguida como uma patologia de temperamento silvestre ou rural, porém surge se estendendo para áreas urbanas. Nos tempos atuais é considerada uma enfermidade endêmica (JAYME et al., 2016). Pastorino et al. (2002) afirma que o Brasil é responsável por aproximadamente $97 \%$ dos casos notificados no continente americano. Em razão da urbanização e da estrutura básica e sanitária deficiente nota-se uma disseminação da doença no Estado do Tocantins, sendo registrado em 2015 casos autóctones no município de Araguaína e em seguida no município de Palmas (JAYME et al., 2016; SILVA et al., 2017).

A LVC tem implicações assoladoras, mesmo com o crescimento de ocorrência da doença e com alto índice de morbilidade e mortalidade, ainda não existe uma forma eficaz para o controle da doença (SOUZA et al., 2013). O cão infectado pela LVC pode não apresentar sintomas, segundo Assis et al. (2010) desenvolve uma adequada resposta imune celular, tornando resistentes à doença; enquanto outros apresentam manifestações clínicas de formas inespecíficas e diversas, incluindo a perda de peso e pêlos, lesões na pele, perda de apetite, anemia, lesões renais e hepáticas, podendo ocorrer ainda unhas quebradiças, atrofia muscular, febre intermitente, podem apresentar também poliartrite, polidipsia, glomerulonefrite e lesões oculares (NOGUEIRA et al., 2009; FONTES et al., 2015).

Devido à variedade de sintomas comuns a outras doenças, a LVC é de difícil diagnóstico clínico, os animais podem não apresentar sintomas ou aparecer somente após meses da contaminação, por esse motivo exames como hemograma e outros são inespecíficos para a doença, e podem apresentar alterações que não são fidedignos a patogenia. Com base nisso acredita-se que os exames parasitológicos, sorológicos e moleculares são os mais indicados para o diagnóstico (SCHIMMING et al., 2012). 
É crucial que exista um diagnóstico específico e sensível para a LVC, Silva (2007) afirma que o diagnóstico clínico é precário e de grande complexibilidade. Diante do exposto, é perceptível que assim como em outros locais no Brasil, necessita de um estudo sobre a incidência de casos de leishmaniose visceral canina na região de Guaraí (TO), o efetivo diagnóstico da doença e ainda se as medidas de prevenção, controle e tratamento estão sendo aplicadas corretamente.

Segundo Silva (2007) normalmente a LVC antecede a doença humana. Diante de tanto necessita-se de atenção especial para que os casos da doença sejam diagnosticados precocemente, além de realizar o controle dos animais acometidos e o controle do vetor.

O objetivo deste artigo é realizar um levantamento de casos confirmados de LVC registrados na Unidade de Controle de Zoonoses (UCZ) do município de Guaraí (TO) avaliando os métodos diagnósticos da doença e sua efetividade pelo parasitológico direto e teste imunocromatográfico.

\section{METODOLOGIA}

Foram selecionados, aleatoriamente, 10 cães na Unidade de Controle de Zoonoses do município de Guaraí, situado na Mesorregião Ocidental do Tocantins e Microrregião de Miracema do Tocantins com coordenadas geográficas $08^{\circ} 50^{\prime} 03^{\prime \prime}$ S e 4830'37"O e altitude de $259 \mathrm{~m}$, sede da 6a Região Administrativa do Estado (IBGE, 2017).

Os animais amostrados eram Sem Raça Definida (SRD), possuía idades diferenciadas entre os indivíduos. A metodologia baseou-se em duas etapas:

\section{Teste Rápido Dual Path Platform - DPP ${ }^{\circledast}$}

Inicialmente, realizou-se a coleta de sangue periférico através da veia cefálica do membro dianteiro e em seguida a pesquisa sorológica para LV canina por Reação de Imunofluorescência Indireta (RIFI), utilizando o kit de imunofluorescência (DPP ${ }^{\circledR}$ LVC Bio-Manguinhos/FIOCRUZ).

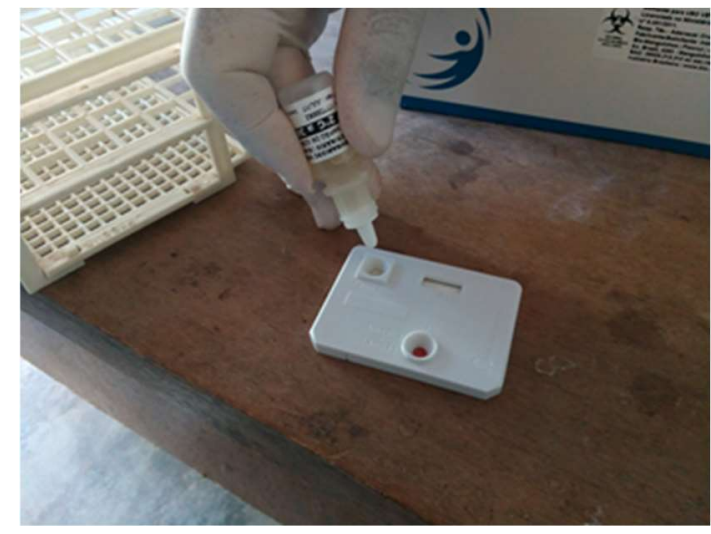

Figura 2: Teste Imunocromatográfico para LVC.

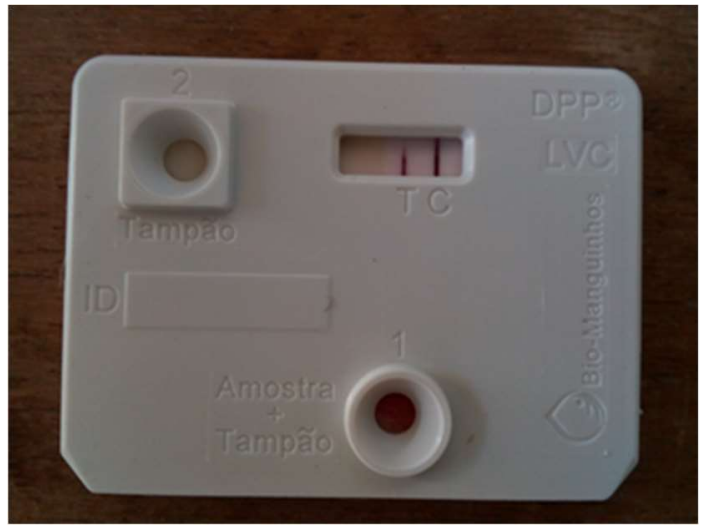

Figura 3: Teste positivo para LVC.

Conforme as orientações do fabricante, o teste $\mathrm{DPP}^{\circledR}$ foi realizado adicionando cerca de $5 \mu \mathrm{L}$ de sangue total ao poço 1 (amostra + tampão), e em seguida foram adicionadas 2 gotas do tampão no mesmo poço. Após 5 minutos as duas linhas azuis, controle (C) e teste (T), desapareceram. A seguir colocou-se 4 
gotas do tampão no poço 2 (tampão), aguardando de 10 a 15 minutos, após esta etapa foi realizada a leitura dos resultados. Para resultados positivos apareceram duas linhas róseas na área controle (C) e teste (T), resultados negativos apenas uma linha rósea no controle (C) (figura 2 e 3 ).

\section{Parasitológico Direto}

O exame parasitológico para a deteç̧ão de formas amastigotas e promastigotas foi realizado nos cães que os testes sorológicos se apresentaram positivos, nos quais coletaram-se as amostras de linfa através de punção aspirativa nos linfonodos da perna de 10 cães (figura 4) e punção aspirativa por medula óssea em 1 cão previamente sedado, neste caso, a sedação foi realizada pela veterinária responsável pela UCZ. Após a colheita de amostra, os esfregaços foram fixados com álcool e corados com Giemsa.

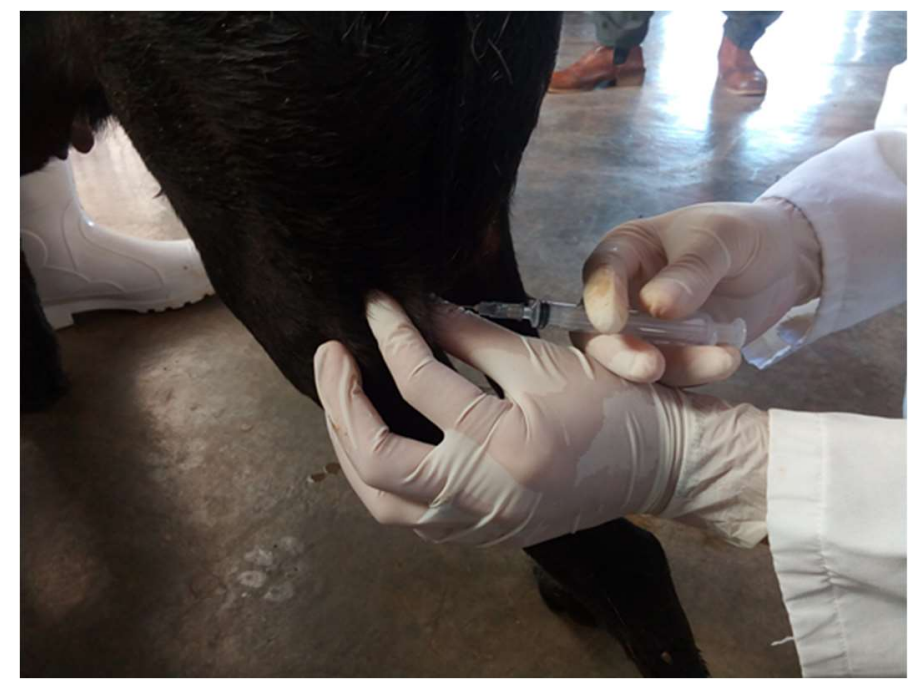

Figura 4: Punção do Linfonodo.

As formas parasitárias de protozoários foram confirmados por meio de busca por até 30 minutos em cada esfregaço em microscópio observando as formas parasitárias em aumento de 40x e 100x. Foram examinadas 20 réplicas de 100 eritrócitos (RBC) por campo, totalizando 2.000 eritrócitos (GODFREY et al.; $1987 ; 1990)$, e a parasitemia determinada pela contagem do número de parasitos visualizados $/ 2.000$ eritrócitos. Os dados morfométricos das formas parasitárias encontradas foram registrados e expressos em $\mu \mathrm{m}$. As análises foram realizadas no Laboratório Multi III, Laboratório de Análises Clínicas do Instituto Educacional Santa Catarina, IESC, Guaraí - TO.

\section{RESULTADOS E DISCUSSÃO}

Nos 10 animais que apresentaram resultados positivos ao Teste Imunocromatográfico DPP ${ }^{\circledR}$ todos foram confirmados no exame parasitológico, onde também algumas lâminas apresentaram reação cruzada sendo possível identificar a presença de Babesia e Ehrlichia em alguns animais (Tabela 01). Todos os animais avaliados apresentavam sintomas característicos como lesões na pele e estado físico debilitado nos exames clínicos.

Embora todos se apresentaram positivos no teste rápido, o resultado diferiu significativamente na 
amostra examinada no parasitológico apresentando prevalência de $100 \%$ para Leishmania, 60\% para Babesia e $30 \%$ para Ehrlichia.

Tabela 1: Resultados do Teste Rápido de Imunocromatografia (DPPR) e da pesquisa de formas amastigotas de Leishmania spp. em punção aspirativa de medula óssea e linfonodo em 10 cães com suspeitas de leishmaniose visceral oriundos do município de Guaraí - TO.

\begin{tabular}{|c|c|c|c|c|}
\hline \multirow{2}{*}{ Animal } & \multirow{2}{*}{$\mathrm{DPPR}^{\circledR}$} & \multicolumn{3}{|c|}{ Parasitológico } \\
\hline & & Leishmania & Babesia & Ehrlichia \\
\hline 1 & + & + & + & - \\
\hline 2 & + & + & + & + \\
\hline 3 & + & + & + & + \\
\hline 4 & + & + & + & - \\
\hline 5 & + & + & - & - \\
\hline 6 & + & + & + & + \\
\hline 7 & + & + & - & - \\
\hline 8 & + & + & - & - \\
\hline 9 & + & + & + & - \\
\hline 10 & + & + & - & - \\
\hline
\end{tabular}

Todos os cães submetidos ao teste rápido imunológico foram soropositivos para Leishmaniose visceral, sendo confirmado no parasitológico direto com visualização de formas amastigotas e promastigotas (Figura 5).

A presença de reações cruzadas foi também apontada em outros estudos. Esta ocorrência é comum, já que esses agentes têm o mesmo vetor como meio de transmissão. Assis et al., (2010) afirma que existe a coinfecção entre L. (L.) chagasi, E. canis e B. canis. Segundo Baneth e Solano-Gallego (2006) o local também pode influenciar, pois os vetores buscam por climas e habitats semelhantes.

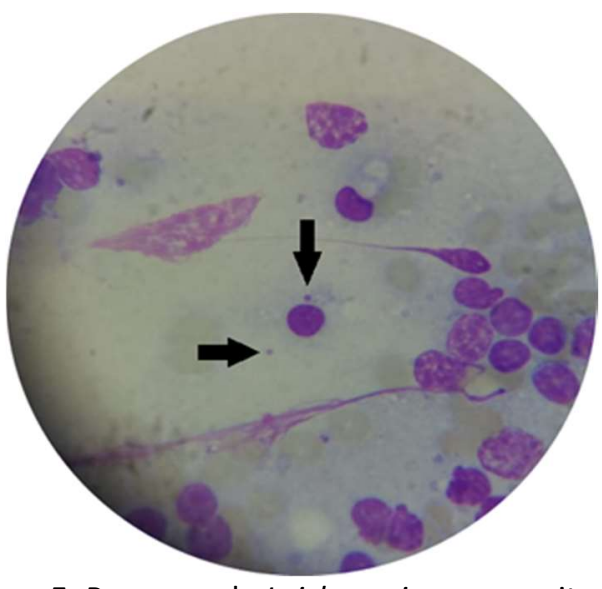

Figura 5: Presença de Leishmania sp. parasitando leucócito (linfonodo).

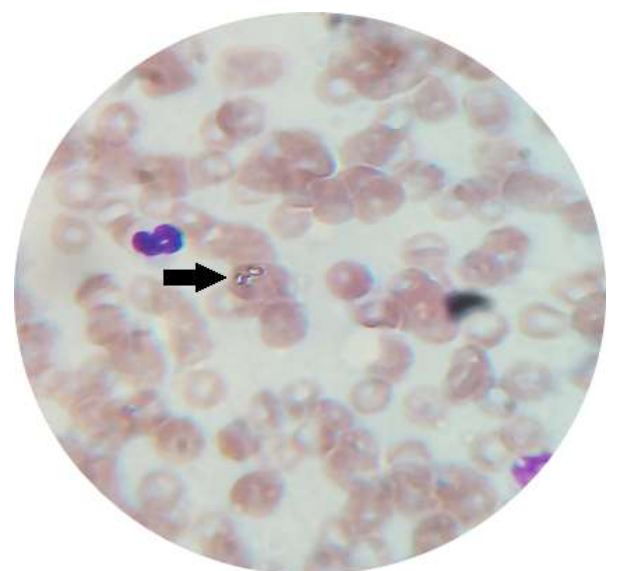

Figura 6: Presença de Babesia canis parasitando hemácia de cão.

Os animais 01, 04, e 09 foram positivos para a infecção de LVC e ainda encontrados no exame direto a presença de Babesia pela punção aspirativa do linfonodo, o que indica a presença de uma co-infecção (Figura 6). Essa observação concorda com os achados de Oliveira et al. (2008), em sua pesquisa foram encontrados os mesmos protozoários parasitando os animais amostrados.

Os organismos do gênero Babesia pertencem ao filo Apicomplexa, ordem Piroplasmida, família Babesiidae. Sua transmissão para o cão é realizada através da alimentação de um vetor ixodídeo Rhipicephalus sanguineus (carrapato castanho do cão) infectado com o agente; e através de transfusões 
sanguíneas de animais infectados (CORRÊA et al., 2005), tendo o período de incubação de 10 a 21 dias. 0 ciclo biológico de Babesia spp. no hospedeiro vertebrado ocorre exclusivamente no interior dos eritrócitos (figura 6).

De acordo com Caeiros (2012) e Corrêa et al. (2005) a infecção por Babesia resultam em anemia e febre que evolui para mucosas pálidas, perda de apetite, depressão. Icterícia, petéquias e hepatoesplenomegalia estão presentes em alguns cães, dependendo do estágio de infecção.

A Babesia é composta por parasitas de hemácias de diferentes animais, B. bigemina e $B$. bovis (bovinos); B. caballi (equinos); B. canis (cães) e B. microti (roedores), sendo que a última ainda não foi encontrada no Brasil. A ocorrência da infecção no ser humano é rara e mais frequentes em pacientes imunossuprimidos (NEVES et al., 2014).

O animal 06 também foi positivo para Leishmania, Babesia e Ehrlichia no exame parasitológico de medula óssea. De acordo com Moreira et al. $(2003 ; 2005)$ em cães portadores de erliquiose, 3,44\% também são parasitados por outros hemoparasitas, a coinfecção contribui no agravo clínico.

Os animais 02 e 03 além da LVC também estavam com a presença de Ehrlichia na punção aspirativa de linfonodo (Figura 7). A presença de Ehrlichia canis em cães sororreagentes para leishmaniose em áreas endêmicas para as duas infecções foi citada no estudo realizado por Souza e Almeida (2008) em Cuiabá-MT. Os autores afirmam que a existência dessa co-infecção agrava o quadro clínico dos animais. Da mesma maneira, os animais podem apresentar anemia, lesões cutâneas e hepatoesplenomegalia.

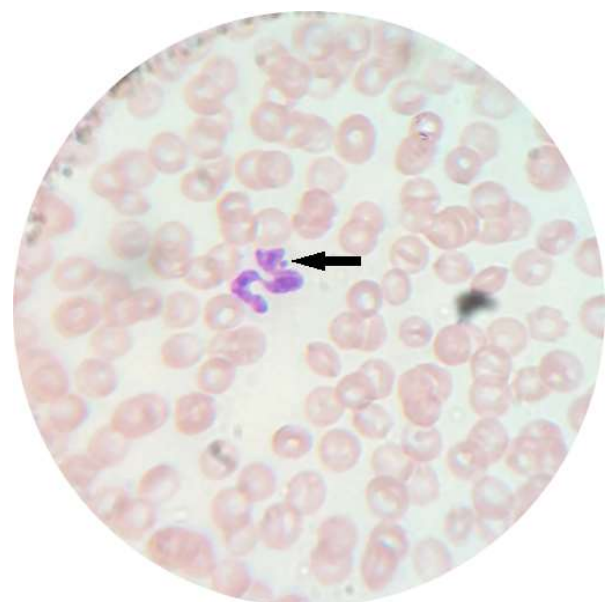

Figura 7: Presença de Ehrliquia canis parasitando um leucócito.

A transmissão das bactérias do gênero Ehrlichia, principalmente pela espécie Ehrlichia canis, agente etiológico da erliquiose monocítica canina, ocorre durante o parasitismo por ninfas e/ou adultos do carrapato Rhipicephalus sanguineus, o qual mantém a bactéria por transmissão transestadial - de uma geração para outra (UENO et al., 2009). A bactéria parasita células de distintas espécies de animais domésticos e silvestres, inclusive o ser humano (MACHADO, 2004).

No estudo realizado por Oliveira et al. (2008) para verificar a existência de reação cruzada entre leishmaniose visceral, erliquiose e babesiose nos testes sorológicos utilizados em programas de controle da leishmaniose visceral humana, amostras de soro canino provenientes de áreas endêmicas e não endêmicas para essa enfermidade foram testadas pela Reação de Imunofluorescência (RIFI) e Ensaio imunoenzimático 
(ELISA). Os autores chegaram à conclusão que os resultados sugere portanto, a presença de uma co-infecção entre os três parasitos citados nas áreas endêmicas e não a reação cruzada entre eles, nos testes sorológicos de RIFI e ELISA descritos.

Os animais 05, 07, 08 e 10 apresentaram resultados positivos apenas para LVC, através da punção aspirativa de linfonodo. A frequência de animais sororreagentes pela reação de IFI é caracterizada pelas manifestações clínicas e outros fatores como sexo e idade. No presente estudo, todos os animais avaliados apresentavam sinais clínicos compatíveis com a doença de Leishmaniose visceral como por exemplo as ulcerações na pele que foram as alterações clínicas mais constantes, como foi demonstrado no estudo de Figueiredo et al. (2014).

Sousa et al. (2014) ao realizar um estudo em 10 cães utilizando o teste rápido imunocromatográfico (DPP ${ }^{\circledR}$ LVC Bio-Manguinhos) e parasitológico direto para pesquisa de formas amastigotas do parasita através da punção de linfonodos, medula óssea e imprint de lesões de pele e de baço em um animal necropsiado, no município de Bom Jesus-PI, detectou a presença de formas amastigotas do parasita em $88,9 \%$ dos animais positivos no teste rápido, sendo que segundo os autores, este pode ser um bom teste de triagem em áreas endêmicas.

Ainda de acordo com o mesmo autor, o teste rápido (DPP ${ }^{\circ}$ ) apresenta maior sensibilidade $(98 \%)$ em animais sintomáticos quando comparado aos animais assintomáticos (47\%). O presente estudo foi realizado com animais sintomáticos e em $100 \%$ dos animais que tiveram resultados positivos ao teste rápido também foram confirmados no exame parasitológico.

\section{CONCLUSÃO}

O estudo realizado permitiu concluir que o teste rápido (DPP ${ }^{\circ}$ ) mostrou-se eficiente, sendo que em todos os animais positivos foram confirmados no exame parasitológico. A presença de outros parasitas como a Babesia e a Erlichia não influenciou no diagnóstico realizado pelo teste sorológico, porém os exames clínicos podem estar relacionados aos sinais clínicos dos outros parasitas. Por esse motivo, é necessário que seja utilizado outros testes para confirmação.

Outros exames podem ser utilizados para confirmar a presença de Leishmania como o ensaio imunoenzimático indireto (ELISA), a reação de imunofluorescência indireta (RIFI), a histoquímica (HE) e a imunoistoquímica (IMIQ) em tecidos de órgãos, como o baço, linfonodo e fígado. Além disso, a Reação em Cadeia pela Polimerase (PCR) das amostras de sangue e dos tecidos pode ser utilizada para comparar e confirmar os diagnósticos negativos e não conclusivos pelos métodos acima.

AGRADECIMENTOS: Agradecemos a todos os envolvidos na pesquisa, em especial, aos funcionários da Unidade de Controle de Zoonoses de Guaraí-TO pelo apoio, pela recepção e pela paciência. Aos alunos de Ciências Biológicas e Biomedicina do Instituto Educacional Santa Catarina/Faculdade Guaraí que contribuíram de alguma maneira em um dos processos da pesquisa. 


\section{REFERÊNCIAS}

ASSIS, J. D.; QUEIROZ, N. M. G. P. D.; SILVEIRA, R. D. C. V. D.; NUNES, C. M.; OLIVEIRA, T. M. F. D. S.; NORONHA JUNIOR, A. C. F. D.; BUZETTI, W. A. S.. Estudo comparativo dos métodos diagnósticos para Leishmaniose Visceral em cães oriundos de Ilha Solteira, SP. Revista Brasileira de Parasitologia Veterinária, p.17-25, 2010.

BANETH, G.; SOLANO-GALLEGO, L.. Leishmaniasis. In: GREENE, C. E.. Infectious diseases of the dog and cat. 4 ed. Philadelphia: Elsevier Saunders, 2012. p.735-748.

BASTOS, T. S. A.; MADRID, D. M. C.; LINHARES, G. F. C.. Aspectos Gerais da Leishmaniose Visceral. Enciclopédia Biosfera, Goiânia, v.11, n.22, p.293, 2015.

CAEIROS, A. P. S.. Detecção de Babesia spp. e de outros hemoparasitas em cães por técnicas morfológicas, serológicas e moleculares, no distrito de Lisboa, Portugal. Dissertação (Mestrado Integrado em Medicina Veterinária) FMV-UTL, Lisboa, 2012.

CORRÊA, A.; NASCIMENTO, M. V.; FARIA, L. S.; BISSOLI, E. D. A. G.; PENA, S. B.. Babesiose Canina: relato de caso. Revista Científica Eletrônica de Medicina Veterinária, Garça, v.3, p.167-171, 2005.

FARIA, A. R.; ANDRADE, H. M.. Diagnóstico de la Leishmaniasis Visceral Canina: grandes avances tecnológicos y baja aplicación práctica. Revista Pan-Amazônica de Saúde, v.3, n.2, p.47-57, 2012.

SOUZA, N. F.; FIGUEIREDO, H. F.; MENESES, A. M. C.; SILVA FILHO, E.; NASCIMENTO, G. G.. Fatores de risco e classificação clínica associados à soropositividade para leishmaniose visceral canina. Ciência Animal Brasileira, Goiânia, v.15, n.1, p.102-106, 2014.

FOCACCIA, R.; VERONESI, R.. Veronesi: tratado de infectologia. In: Veronesi: tratado de infectologia. 2005. p.898-899.

FONTES, S. D.; SILVA, A. S. A.. Leishmaniose Visceral Canina. ANAIS SIMPAC, v.3, n.1, 2015.

GODFREY JUNIOR, R. D.; FEDYNICH, A. M.; PENCE, D. B.. Effects of host and spatial factors on a haemoproteid community in mourning doves from western Texas. Journal of Wildlife Diseases, v.26, n.4, p.435-441, 1990.

GODFREY JUNIOR, R. D.; FEDYNICH, A. M.; PENCE, D. B.. Quantification of hematozoa in blood smears. Journal of wildlife diseases, v.23, n.4, p.558-565, 1987.

GONTIJO, C. M. F.; MELO, M. N.. Leishmaniose visceral no Brasil: quadro atual, desafios e perspectivas. Revista Brasileira de Epidemiologia, v.7, p.338-349, 2004.

IBGE. Instituto Brasileiro de Geografia e Estatística. Estimativas populacionais para os municípios e para as Unidades da Federação brasileiros. 2017.

JAYME, M. S. D.. Perfil Epidemiológico dos casos de Leishmaniose Visceral em Palmas, Tocantins no período de 2007-2014. Rev. Pat. Tocantins, v.13, n.1, 2016.
MACHADO, R. Z.. Erliquiose canina. Revista Brasileira Parasitologia Veterinária, v.13, p.53-57, 2004.

MONTEIRO, É. M.; SILVA, J. C. F. D.; COSTA, R. T. D.; COSTA, D. C.; BARATA, R. A.; PAULA, E. V. D.; DIAS, E. S.. Visceral leishmaniasis: a study on phlebotomine sand flies and canine infection in Montes Claros, State of Minas Gerais. Revista da Sociedade Brasileira de Medicina Tropical, v.38, n.2, p.147152, 2005.

MOREIRA, S. M.; BASTOS, C. V.; ARAÚJO, R. B.; SANTOS, M.; PASSOS, L. M. F. Retrospective study (1998-2001) on canine ehrlichiosis in Belo Horizonte, Minas Gerais, Brazil. Arquivo Brasileiro de Medicina Veterinária e Zootecnia, Belo Horizonte, v.55, n.2, p.141-147, 2003.

MOREIRA, S. M.; MACHADO, R.; PASSOS, L. F.. Detection of Ehrlichia canis in bone marrow aspirates of experimentally infected dogs. Ciência Rural, Santa Maria, v.35, n.4, p.958960, 2005.

NEVES, D. P.; FILIPPIS, T.. Parasitologia Básica. 3 ed. São Paulo: Atheneu, 2014.

NOGUEIRA J. L.; SILVA, M. V. M.; PASSOS, C. C.; AMBRÓSIO, C. E.. A Importância Da Leishmaniose Visceral Canina Para A Saúde Pública: Uma Zoonose Reemergente. Revista Científica Eletrônica De Medicina Veterinária, v.7, n.13, p.12, 2009.

OLIVEIRA, T. M. F.; FURUTA, P. I.; CARVALHO, D. D.; MACHADO, R. Z.. Estudo da reatividade cruzada em amostras de soro de cães positivos para Leishmania sp., Babesia canis e Ehrlichia canis, pelo ensaio imunoenzimático indireto e pela reação de imunofluorescência indireta. Revista Brasileira de Parasitologia Veterinária, p.7-11, 2008.

PASTORINO, A. C.; JACOB, C. M. A.; OSELKA, G. W.; CARNEIRO-SAMPAIO, M. M. S.. Leishmaniose visceral: aspectos clínicos e laboratoriais. J Pediatr, v.78, n.2, p.120-7, 2002.

SCHIMMING, B. C.; SILVA, J. R. C. P.. Leishmaniose visceral canina: revisão de literatura. Revista científica eletrônica de medicina veterinária, p. 1-17, 2012.

SILVA, F. S.. Patologia e patogênese da leishmaniose visceral canina. Revista Trópical - Ciências Agrárias e Biológicas, v.1, n.1, p.20, 2007.

SILVA, K. B. M.; CASTRO, J. G. D.; CALABRESE, K.; SEIBERT, C. S.; NASCIMENTO, G. N.; MARIANO, S. M. B.; SANTOS, M. G.. Análise espacial da leishmaniose visceral no município de Palmas, Tocantins, Brasil. Hygeia, v.13, n.25, p.18-29, 2017.

SILVINO, A. C. S.; SILVA, K. B.; SOUSA-PAULA, L. C.; DIAS, R. V.; BRAGA, P. E. T.. Caracterização de flebotomíneos em bairros de Sobral, Ceará. Revista da Biologia, v.17, n.2, p.1217, 2017.

SOUSA, R. A.; ALVES, N. R.; ALBANO, S. G. C.; RÊGO, M.S.; MACHADO, L. P.. Teste rápido imunocromatográfico no diagnóstico da Leishmaniose visceral canina no município de Bom Jesus, Piauí. Enciclopédia Biosfera, Goiânia, v.10, n.19, p.1733, 2014. 
SOUSA, V. R. F.; ALMEIDA, A. B. P. F.. Co-infecção entre leishmaniose visceral e ehrlichiose monocítica em cães de Cuiabá, Mato Grosso. Acta Scientiae Veterinariae, v.36, n.2, 2008.

SOUZA, Y. C. P.; CARVALHO, A. F. S.; CARVALHO, A. L. R.; MANSUR, V. F. R. Testes Diagnósticos para Leishmaniose Visceral: Atualidades e Perspectiva. Revista Científica
Eletrônica de Medicina Veterinária, São Paulo, v.11, n.21, 2013.

UENO, T. E. H.; AGUIAR, D. M.; PACHECO, R. C.; RICHTZENHAIN, L. J.; RIBEIRO, M. G.; PAES, A. C.; MEGID, J.; LABRUNA, M. B.. Ehrlichia canis em cães atendidos em hospital veterinário de Botucatu, Estado de São Paulo, Brasil. Revista Brasileira de Parasitologia Veterinária, v.18, n.3, p.57-61, 2009.

A CBPC - Companhia Brasileira de Produção Científica (CNPJ: 11.221.422/0001-03) detém os direitos materiais desta publicação. Os direitos referem-se à publicação do trabalho em qualquer part do mundo, incluindo os direitos às renovações, expansões e disseminações da contribuição, bem como outros direitos subsidiários. Todos os trabalhos publicados eletronicamente poderão posteriormente ser publicados em coletâneas impressas sob coordenação da Cognitionis Publishing, da Companhia Brasileira de Produção Científica e seus parceiros autorizados. Os (as) autores (as) preservam os direitos autorais, mas não têm permissão para a publicação da contribuição em outro meio, impresso ou digital, em português ou em tradução. 